\title{
Influence of total face, facial and nasal masks on short-term adverse effects during noninvasive ventilation*,**
}

\author{
Influência das máscaras facial total, facial e nasal nos \\ efeitos adversos agudos durante ventilação não-invasiva \\ Marcelo Alcantara Holanda, Ricardo Coelho Reis, \\ Georgia Freire Paiva Winkeler, Simone Castelo Branco Fortaleza, \\ José Wellington de Oliveira Lima, Eanes Delgado Barros Pereira
}

\begin{abstract}
Objective: Failure of noninvasive ventilation (NIV) has been associated with short-term adverse effects related to the use of masks. The aim of this study was to compare the incidence, type and intensity of adverse effects, as well as the comfort, of total face masks (TFMs), facial masks (FMs) and nasal masks (NMs) during NIV. Methods: This was a randomized crossover trial involving 24 healthy volunteers submitted to six sessions of NIV in bilevel positive airway pressure mode using the TFM, FM and NM masks at low and moderate-to-high pressure levels. A written questionnaire was applied in order to evaluate eleven specific adverse effects related to the use of the masks. Comfort was assessed using a visual analog scale. The $\mathrm{CO}_{2}$ exhaled into the ventilator circuit was measured between the mask and the exhalation port. Results: The performance of the TFM was similar to that of the NM and FM in terms of comfort scores. Higher pressure levels reduced comfort and increased adverse effects, regardless of the mask type. When the TFM was used, there were fewer air leaks and less pain at the nose bridge, although there was greater oronasal dryness and claustrophobia. Air leaks were most pronounced when the FM was used. The partial pressure of exhaled $\mathrm{CO}_{2}$ entering the ventilator circuit was zero for the TFM. Conclusions: The shortterm adverse effects caused by NIV interfaces are related to mask type and pressure settings. The TFM is a reliable alternative to the NM and FM. Rebreathing of $\mathrm{CO}_{2}$ from the circuit is less likely to occur when a TFM is used.
\end{abstract}

Keywords: Intermittent positive-pressure ventilation; Masks/adverse effects; Respiratory insufficiency; Equipment failure analysis.

\section{Resumo}

Objetivo: Falhas da ventilação não-invasiva (VNI) têm sido relacionadas a efeitos adversos agudos do uso de máscaras. 0 objetivo deste estudo foi comparar a incidência, tipo e intensidade de eventos adversos e conforto das máscaras facial total (MFT), facial (MF) e nasal (MN). Métodos: Estudo randomizado, tipo cruzado, em 24 voluntários sadios submetidos a seis períodos de $\mathrm{VNI}$, modo bilevel positive airway pressure em ajustes de baixa e moderada a alta pressão. Foi aplicado um questionário de avaliação de onze eventos adversos especificamente relacionados ao uso das máscaras. 0 conforto foi avaliado por escala visual analógica. $0 \mathrm{CO}_{2}$ exalado no circuito foi medido entre a conexão da máscara e o orifício de exalação. Resultados: A MFT teve desempenho similar a MF e MN quanto a escores de conforto. A aplicação de pressões mais altas reduziu o conforto e aumentou a incidência e a intensidade dos eventos adversos, independentemente do tipo de máscara. A MFT teve melhor desempenho quanto a vazamentos e dor no nariz e pior resultado quanto ao ressecamento oronasal e claustrofobia. A MF teve o pior resultado quanto a vazamentos. A pressão parcial do $\mathrm{CO}_{2}$ exalado no circuito permaneceu em zero com a MFT. Conclusões: Os eventos adversos agudos causados pelas interfaces de VNl são relacionados ao tipo de máscara e aos parâmetros de pressão. A MFT é uma alternativa confiável às $\mathrm{MF}$ e $\mathrm{MN}$. A reinalação de $\mathrm{CO}_{2}$ a partir do circuito é menos provável de ocorrer com a MFT.

Descritores: Ventilação com pressão positiva intermitente; Máscaras/efeitos adversos; Insuficiência respiratória; Análise de falha de equipamento.

\footnotetext{
* Study carried out in the Laboratory for Clinical Research and the Pulmonology Department, Federal University of Ceará Walter Cantídio University Hospital, Fortaleza, Brazil.

Correspondence to: Marcelo Alcantara Holanda. Rua Coronel Jucá, 700/30, CEP 60170-320, Fortaleza, CE, Brasil.

Tel 5585 9973-0714. Fax 5585 4011-5647. E-mail: marceloalcantara2@gmail.com

Financial support: None.

Submitted: 27 February 2008. Accepted, after review, 8 July 2008.

${ }^{* *}$ A versão completa em português deste artigo está disponível em www.jornaldepneumologia.com.br
} 


\section{Introduction}

Noninvasive ventilation (NIV) using positive pressure is now considered the first-line treatment for acute respiratory failure (ARF), reducing the need for endotracheal intubation and improving survival in selected groups of patients such as those with COPD exacerbation and acute cardiogenic pulmonary edema. ${ }^{(1-3)}$ Nevertheless, NIV fails in up to 40 to $60 \%$ of cases. ${ }^{(2,4-9)}$ Interface-related problems are the most common adverse effects, accounting for 50-100\% of all complications associated with NIV. ${ }^{(10,11)}$ In addition, 25-33\% of appropriately selected patients adapt poorly to NIV, principally due to problems related to the mask. Such problems include excessive air leaks, excessive air pressure on the face, claustrophobia, $\mathrm{CO}_{2}$ rebreathing, skin lesions on the bridge of the nose, facial pain and oronasal dryness. ${ }^{(10-12)} \mathrm{A}$ comfortable fit of the interface is of paramount importance to avoid adverse effects.

A total face mask (TFM), also known as a "full face mask", has recently been developed and is designed to minimize side effects such as air leaks. Two recent studies have shown promising clinical results using TFMs in patients with ARF. ${ }^{(13,14)}$ However, this interface has not yet been compared with standard nasal masks (NMs) and facial masks (FMs). Many different types of commercial masks are now available. ${ }^{(15,16)}$

The choice of a particular NIV mask for a patient in ARF is, in most cases, empirical. Comparative studies to address specific characteristics and performances of different interfaces, including short-term adverse effects, can provide additional information to help physicians choose the most appropriate mask for a particular patient, increasing the probability of NIV success, as well as helping manufacturers design masks that are more efficient and well tolerated. ${ }^{(17)}$

The aim of this study was to compare TFMs, FMs and NMs in terms of the incidence, type and intensity of short-term adverse effects, as well as their comfort, when used during NIV.

\section{Methods}

\section{Subjects}

The study population comprised 24 healthy nonsmoking volunteers, aged 18 years or older.
The volunteers were chosen so that the results would not be influenced by confounding factors unrelated to the masks, such as sleep disordered breathing, symptoms of respiratory failure and invasive procedures, as well as the stressful intensive care unit or emergency room environments to which patients with ARF are exposed. ${ }^{(18)}$ For convenience and to avoid any misunderstanding of the specific short-term adverse effects being investigated, all volunteers were selected from among health professionals or health sciences students. The exclusion criteria were as follows: presenting a medical history or physical examination finding of ear, nose, mouth, teeth, cranial, facial or respiratory diseases; having prior experience or deep knowledge of NIV management; and having previously been submitted to NIV as a patient or volunteer. The local institutional review board approved the study, and written informed consent was obtained from each subject.

\section{Equipment and procedures}

All interfaces were from the same manufacturer (Respironics, Inc., Murrysville, PA, USA). Figure 1 shows the three masks tested in the present study, using one of the volunteers as a model: the TFM, the NM (Disposable Contour Deluxe) and the FM. All have a vinyl mask cushion and a tubing port (for pressure monitoring; this remained closed). The TFM has a pressure pickoff (allows connection of a proximal pressure line or monitoring device) and, positioned over the cheeks, two built-in exhalation ports (these remained open, as recommended by the manufacturer). The internal volumes of the NM, FM and TFM are $105 \mathrm{~mL}, 335 \mathrm{~mL}$ and $1500 \mathrm{~mL}$, respectively. The study was carried out in a quiet, air-conditioned room in the clinical research laboratory of a teaching hospital. Subjects lay on a hospital bed with $45^{\circ}$ of head elevation. Although the TFM is available in only one size (designed to fit most faces), the other two masks are available in small, medium and large sizes; the most appropriate size was chosen for each patient. Interface fitting was performed according to the manufacturer instructions. All masks were manually adapted to the face in a gentle manner and then connected to the ventilator (BiPAP Vision; Respironics, Inc., Murrysville, PA, USA), which was used in the bilevel positive airway pressure (BiPAP) mode. The ventilator 


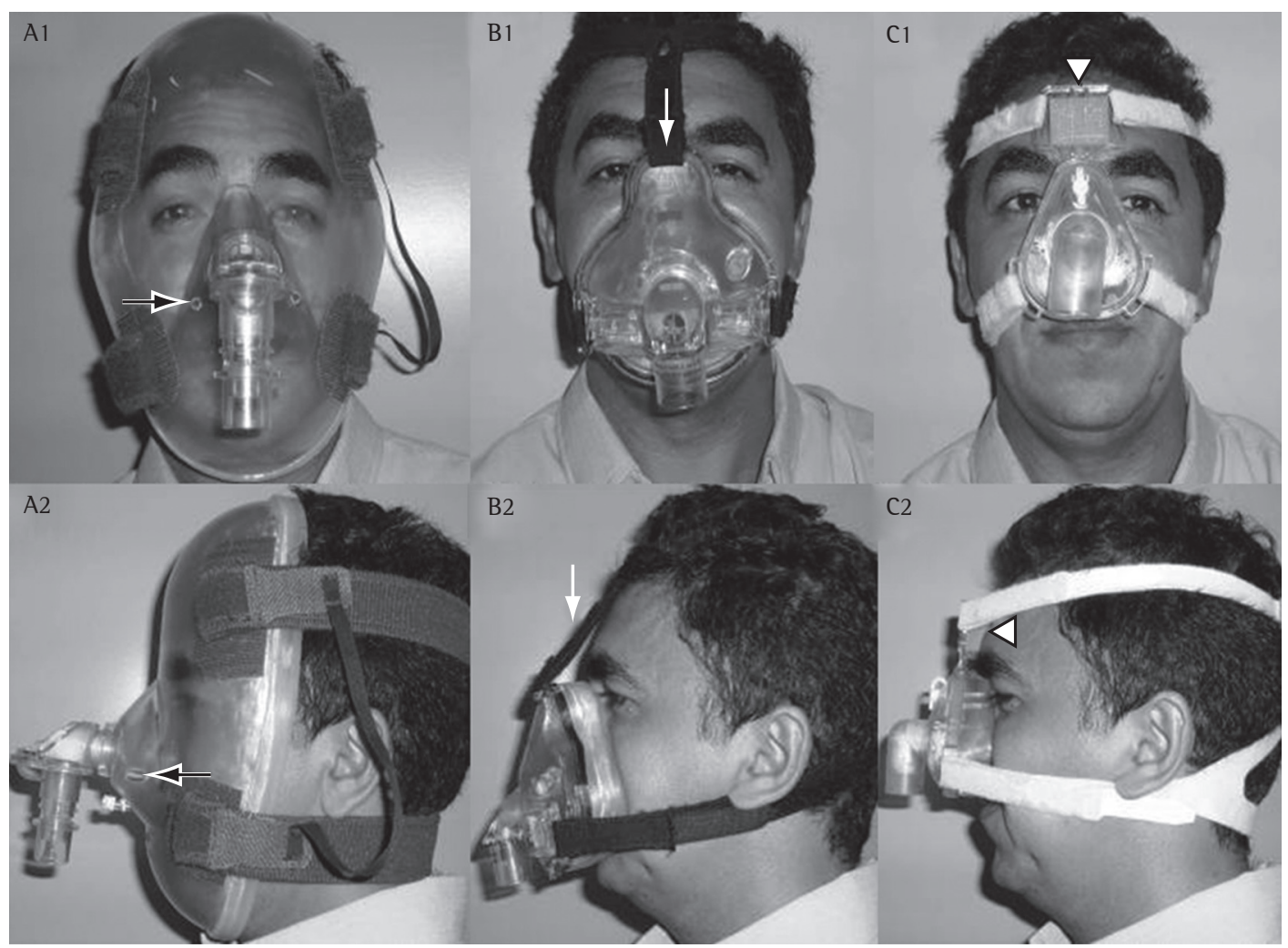

Figure 1 - Frontal and lateral views of the three types of NIV masks modeled by a volunteer: A1/A2, the total face mask (TFM); B1/B2, the facial mask (FM); and $\mathrm{C} 1 / \mathrm{C} 2$, the nasal mask (NM). One detail of each mask is indicated: black arrow, built-in exhalation port of the TFM; white arrow, central strap of the FM; and white arrowhead, foam forehead spacer of the NM.

circuit was the same for all masks. No supplemental oxygen or heated humidity was used. Synchrony between the patient and the ventilator was confirmed by visual inspection of the thorax, as well as of the pressure-time curve and flow-time curve on the ventilator display. Only then was the mask affixed to the head, firmly but not tightly. Once secure, the mask was gently readjusted as needed to maximize comfort. Installation and adaptation of the NIV required 5 to $10 \mathrm{~min}$. A team consisting of one pulmonologist and two respiratory therapists with experience in NIV was in charge of the protocol.

\section{Masks short-term adverse effects and comfort}

Since there are no standardized, validated questionnaires available, we used a written questionnaire developed by our group specifically to assess short-term adverse effects induced by NIV masks. Part of the questionnaire was based on a previous study that evaluated the side effects of using continuous positive airway pressure (CPAP) to treat obstructive sleep apnea syndrome and included six questions pertaining specifically to mask-related aspects (pressure, skin irritation, claustrophobia, air leaks, dry mouth/throat and nasal dryness/congestion). ${ }^{(19)}$ We divided the question regarding air leaks into two parts (to distinguish between leaks around the eyes and leaks around the mouth), and we included four additional questions designed to evaluate pain at the points where the mask is in contact with the face. Therefore, the questionnaire consisted of eleven questions. The volunteers were asked to score each short-term adverse effect as not a problem (0), a slight problem (1), a moderate problem (2) or a major problem (3). All volunteers were encouraged to include additional comments regarding aspects of the mask not addressed by the questionnaire. Appendix 1 shows the questionnaire in detail. The volun- 
teers registered their perception of mask comfort on a $10-\mathrm{cm}$ visual analog scale, 10 representing maximum comfort and 0 representing maximum discomfort. The following explanation was given to the volunteers: "A score of 10 indicates normal comfortable respiration, as if you were breathing without a mask, and a score of 0 indicates the maximum discomfort you could imagine."

\section{Study design}

The study was a randomized crossover experimental trial. The crossover study design was used in order to allow the subjects to participate in all three mask trials consecutively. Washout periods were employed in order to avoid the influence of one mask trial on the others in the same indi- vidual. In this type of design, each subject crossing over serves as a control. The order effects were minimized by the randomization of the trials, which were tested in six possible sequences. The spontaneous BiPAP mode was used. Two pressure settings were tested for a total time of 10-15 min each: a low-pressure (LoP) setting, with an expiratory positive airway pressure (EPAP) of $6 \mathrm{cmH}_{2} \mathrm{O}$ and an inspiratory positive airway pressure (IPAP) of $11 \mathrm{cmH}_{2} \mathrm{O}$; and a moderate-to-high-pressure (MoHiP) setting, with an EPAP of $10 \mathrm{cmH}_{2} \mathrm{O}$ and an IPAP of $15 \mathrm{cmH}_{2} \mathrm{O}$. The last 5 min of each trial was considered the study period, assuming that the volunteer had fully adapted by that time. In order to prioritize subject comfort, as well as to reproduce everyday practices (ours and those of other experts) for patient acclimatization to NIV,
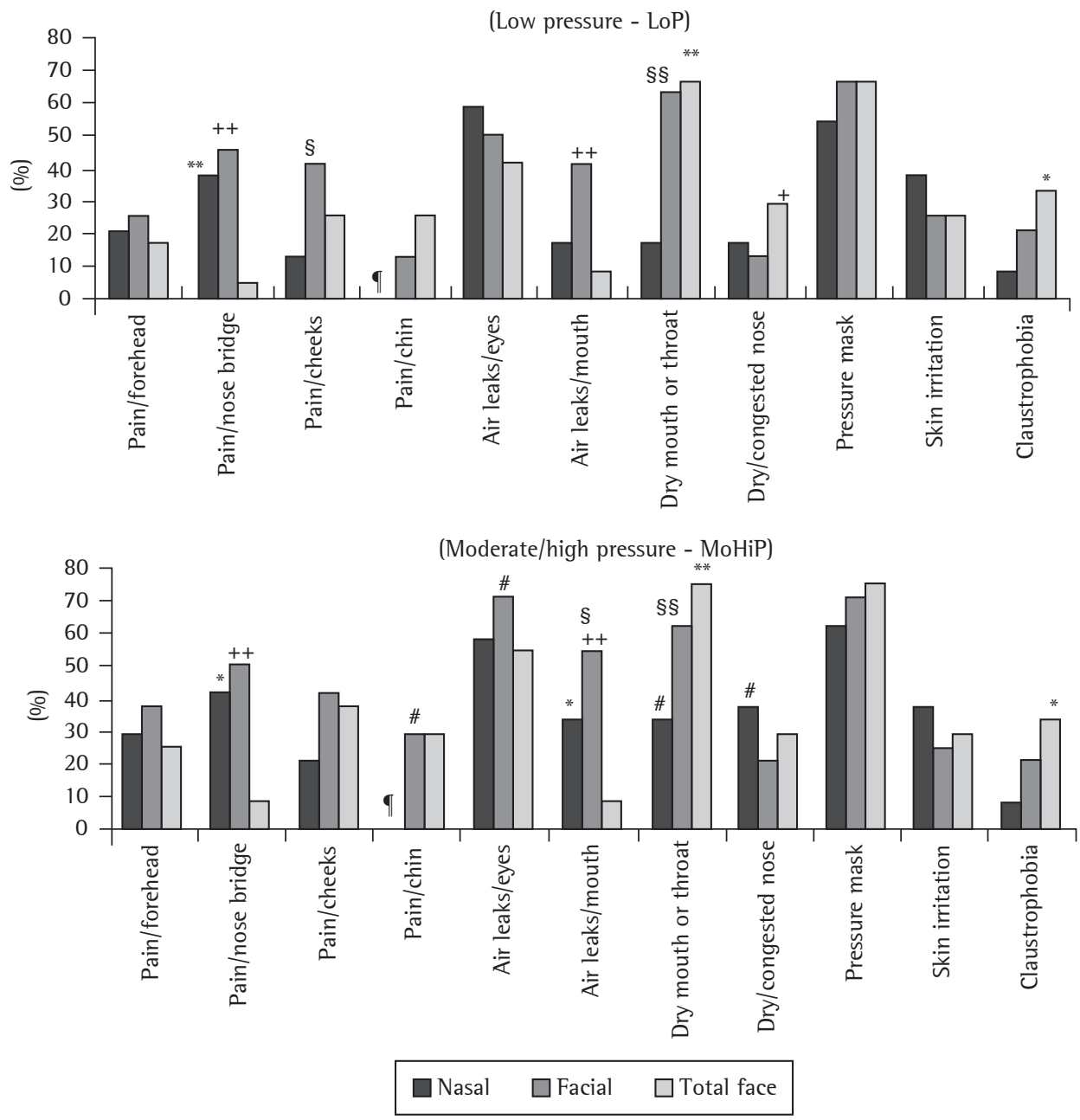

Figure 2 - Incidence of short-term adverse effects by mask type and pressure setting. LoP: low pressure; MoHiP: moderate-to-high pressure; NM: nasal mask; TFM: total face mask; M: facial mask. $\mathrm{p}<0.05:{ }^{*} \mathrm{NM}$ vs. TFM; +FM vs. TFM; ${ }^{\circledR} \mathrm{NM}$ vs. FM; " $\mathrm{HoP}$ vs. MoHiP. $\mathrm{p}<0.01:{ }^{* *} \mathrm{NM}$ vs. TFM; ${ }^{++} \mathrm{FM}$ vs. TFM; ${ }^{\circledR} \mathrm{NM}$ vs. FM; 'not applicable to the NM. 
Table 1 - Short-term adverse effect scores by mask type and pressure setting. ${ }^{2}$

\begin{tabular}{|c|c|c|c|c|}
\hline Effect & Pressure setting & Nasal mask & Facial mask & Total face mask \\
\hline \multirow[t]{2}{*}{ 1. Pain on the forehead } & LoP & $0(0-0)$ & $0(0-0.5)$ & $0(0-0)$ \\
\hline & MoHiP & $0(0-1)$ & $0(0-1)^{*, \S \S}$ & $0(0-0.5)$ \\
\hline \multirow[t]{2}{*}{ 2. Pain at the bridge of the nose } & LoP & $0(0-1)^{+}$ & $0.5(0-1)$ & $0(0-0)$ \\
\hline & MoHiP & $0(0-1)^{+}$ & $0.5(0-1)^{\S \S}$ & $0(0-0)$ \\
\hline \multirow[t]{2}{*}{ 3. Pain on the cheeks } & LoP & $0(0-0)$ & $0(0-1)$ & $0(0-0.5)$ \\
\hline & MoHiP & $0(0-0)$ & $0(0-1)$ & $0(0-1)$ \\
\hline \multirow[t]{2}{*}{ 4. Pain on the chin } & LoP & NA & $0(0-0)$ & $0(0-0.5)$ \\
\hline & MoHiP & NA & $0(0-1)^{*}$ & $0(0-1)$ \\
\hline \multirow[t]{2}{*}{ 5. Air leaks around the eyes } & LoP & $1(0-1)$ & $0.5(0-1.5)^{4}$ & $0(0-1)$ \\
\hline & MoHiP & $1(0-1)$ & $1.5(0-2.5)^{* *, S}$ & $1(0-1.5)$ \\
\hline \multirow[t]{2}{*}{ 6. Air leaks around the mouth } & LoP & $0(0-0)$ & $0(0-1)^{\uparrow, \S \S}$ & $0(0-0)$ \\
\hline & MoHiP & $0(0-1)^{+}$ & $1(0-1.5)^{*, 4, \$ \S}$ & $0(0-0)$ \\
\hline \multirow[t]{2}{*}{ 7. Dry mouth or throat } & LoP & $0(0-0)$ & $1(0-1)^{4}$ & $1(0-1)^{++}$ \\
\hline & MoHiP & $0(0-1)^{*}$ & $1(0-1)$ & $1(0.5-2)^{++}$ \\
\hline \multirow[t]{2}{*}{ 8. Dry or congested nose } & LoP & $0(0-0)$ & $0(0-0)$ & $0(0-1)^{\S}$ \\
\hline & MoHiP & $0(0-1)^{*}$ & $0(0-0)$ & $0(0-1)$ \\
\hline \multirow[t]{2}{*}{ 9. Pressure from the mask } & LoP & $1(0-1)$ & $1(0-1)^{4}$ & $1(0-1.5)^{+}$ \\
\hline & MoHiP & $1(0-1)^{*}$ & $1(0-2)^{*, \mathbb{q}}$ & $1(0.5-2)^{++}$ \\
\hline \multirow[t]{2}{*}{ 10. Skin irritation } & LoP & $0(0-1)$ & $0(0-0.5)$ & $0(0-0.5)$ \\
\hline & MoHiP & $0(0-1)$ & $0(0-0.5)$ & $0(0-1)$ \\
\hline \multirow{2}{*}{ 11. Claustrophobia } & LoP & $0(0-0)$ & $0(0-0)$ & $0(0-1)^{+}$ \\
\hline & MoHiP & $0(0-0)$ & $0(0-0)$ & $0(0-1)^{+, \$}$ \\
\hline
\end{tabular}

${ }^{a}$ Data shown as median and interquartile range; the number of short-term adverse effects ranged from 0 to 3 . LoP: Low pressure; MoHiP: Moderate to high pressure; NA: not applicable. ${ }^{*} p<0.05$ and ${ }^{* *} p<0.01$ (LoP vs. MoHiP within the same mask). ${ }^{+} p<0.05$ and ${ }^{++} p<0.01$ (NM vs. TFM at the same pressure setting); ${ }^{s} p<0.05$ and ${ }^{\$ s} p<0.01$ (FM vs. TFM at the same pressure setting); and $\mathrm{f} p<0.05$ (NM vs. FM at the same pressure setting).

the LoP setting was always applied first followed by the MoHiP setting. ${ }^{(6)}$ The washout period of spontaneous breathing, allowed between masks trials in order to avoid carryover effects, was $10 \mathrm{~min}$. The respiratory rate, peripheral oxygen saturation, heart rate and airway pressure in the circuit proximal to the mask were continuously monitored. We measured the exhaled $\mathrm{CO}_{2}$ between the mask and the end of the ventilator circuit (which included the exhalation port) by interposing a capnograph (Dixtal Biomédica, Manaus, Brazil) in order to evaluate the potential for the accumulation and rebreathing of $\mathrm{CO}_{2}$ from the circuit. ${ }^{(12,20)}$

\section{Outcome variables}

Masks were compared in terms of their overall comfort, the short-term adverse effects related to their use and their physiological parameters. To evaluate the masks in terms of overall comfort, the mean visual analog scale comfort scores were compared. To evaluate short-term adverse effects, masks were compared in terms of the incidence and the intensity of each shortterm adverse effect related to their use.

\section{Statistical analysis}

The comfort, short-term adverse effect incidence/intensity and the physiological variables were compared in two ways: between the two pressure settings (LoP vs. MoHiP) within the same mask trial; and between two different masks at the same pressure setting. The latter type of comparison was made only if there were no carryover effects between mask trials. All comparisons were paired. The scores were evaluated for normal distribution using the Kolmogorov-Smirnov test. If the data were not normally distributed, nonparametric tests were applied. McNemar's test was used for comparisons of the incidence of the short-term adverse effects. The Wilcoxon signed rank test for paired variables was used for comparison of the shortterm adverse effect scores. The ANOVA for a crossover trial was applied for comparisons of 
the physiological variables. The level of statistical significance was set at $p<0.05$.

\section{Results}

The mean age of the study subjects was 25.7 years (range, 18 to 35 years). Half (12) of the volunteers were women. The mean body mass index of the volunteers was $24.24 \mathrm{~kg} / \mathrm{m}^{2}$ (range, 19.23 to $30.78 \mathrm{~kg} / \mathrm{m}^{2}$ ). There were no carryover effects among the mask trials. No volunteer asked to leave the trial.

No significant differences were observed among the masks in terms of the comfort scores, although the MoHiP setting was reportedly less comfortable than the LoP setting: NM $(7.13 \pm$ 1.54 vs. $7.54 \pm 1.61 ; p=0.01)$, FM $(6.54 \pm 1.61$ vs. $7.50 \pm 1.32 ; p<0.001)$ and TFM $(6.50 \pm$ 1.92 vs. $7.25 \pm 2.19 ; p=0.001$ ).

Figure 2 shows the incidence of the shortterm adverse effects by mask type and pressure setting. Table 1 shows the scores (median and interquartile range) for the short-term adverse effects. The TFM performed best concerning pain at the bridge of the nose and air leaks, although it presented the worst performance in terms of oronasal dryness and claustrophobia.

The following adverse effects, not addressed by the questionnaire, were written in by the volunteers: inability to speak ( 3 for the NM, 1 for the FM and 1 for the TFM); pressure on the ear ( 3 for the NM, 2 for the FM and 3 for the TFM); pain above the upper lip ( 2 for the NM); eye irritation ( 2 for the FM and 3 for the TFM); neck discomfort ( 1 for the TFM); dryness of the lips, ( 1 for the NM); overinflation of the cheeks, ( 1 for the FM); and pressure on the paranasal sinus ( 1 for the NM).

The mask trials did not differ significantly in terms of respiratory rate, peripheral oxygen saturation and heart rate. When the TFM was used, the partial pressure of exhaled $\mathrm{CO}_{2}$ entering the circuit remained at zero in all trials. The partial pressure of exhaled $\mathrm{CO}_{2}$ entering the circuit was less when the FM was used than when the NM was used: $27 \mathrm{mmHg}$ vs. $33 \mathrm{mmHg}$ for the LoP setting ( $\mathrm{p}=0.02)$; and $24 \mathrm{mmHg} v s .31 \mathrm{mmHg}$ for the MoHiP setting $(p=0.012)$.

\section{Discussion}

In this randomized crossover trial involving healthy volunteers, the perceived comfort of the
TFM was similar to that of the NM and FM. The TFM performed best concerning unpleasant air leaks around the mouth and pain at the bridge of the nose. On the other hand, use of the TFM was more often associated with claustrophobia and oronasal dryness. The FM presented the poorest performance in terms of unpleasant air leaks. The NM presented the lowest incidence of oronasal dryness. The partial pressure of $\mathrm{CO}_{2}$ exhaled into the circuit remained at zero when the TFM was used.

Some investigators have used bench models and trials involving volunteers to assess the performance of NIV interfaces in terms of the mechanical properties of masks and the physiological effects of their use. ${ }^{(21-24)}$ Other authors have studied the chronic side effects of NM use in sleep apnea syndrome patients treated with CPAP. ${ }^{(25,26)}$ To our knowledge, this is the first study designed to assess short-term adverse effects related to the use of NIV masks and to compare the TFM, FM and NM in healthy volunteers.

There have been few controlled studies comparing NIV masks. One group of authors evaluated the effects of three types of interfaces (FM, NM and nasal pillows) in 30-min runs of NIV in stable hypercapnic patients. ${ }^{(27)}$ The authors found that the NM was the most well accepted and obtained the highest comfort scores, although the FM was more efficient in lowering $\mathrm{CO}_{2}$. Another group compared the performance of NMs and FMs in patients with ARF in a randomized trial. The FM performed better with less intolerance, although overall comfort was similar. ${ }^{(28)}$ Yet another group of authors compared NIV delivered for $15 \mathrm{~min}$ in bilevel mode via NMs or FMs in 14 patients with COPD and found no difference in terms of comfort. ${ }^{(29)}$ The three comparative studies cited above did not include an evaluation of the specific adverse effects of the masks. In our study, comfort scores were similar for the three masks, despite differences in terms of the specific short-term adverse effects caused. We believe the application of specific questions addressing a variety of adverse effects provides more information about individual mask components than do global comfort scores.

The TFM performed best concerning pain at the bridge of the nose. This side effect might indicate the propensity for skin damage to occur 
in this point of mask contact with the face. Skin lesion at the site of mask contact is the most common complication of NIV. ${ }^{(11)}$ The use of the TFM might help avoid this complication. lts headgear and design result in more evenly distributed pressure on the anterior contour of the face, avoiding excessive pressure on any particular structure. ${ }^{(13)}$

The FM presented the highest incidence of unpleasant air leaks, whereas the TFM performed best in this respect. This result might be clinically relevant, since excessive air leaks can predispose to NIV failure. ${ }^{(11)}$ Our findings suggest that the TFM provides better NIV efficacy than does the FM in patients with ARF, due to the fact that the TFM allows higher pressure levels to be used without the danger of massive leaks. ${ }^{(14)}$

Oronasal dryness was less frequently reported when the NM was used than when the TFM or the FM was used. This might be attributable to the higher flow rates needed to compensate for the air leakage through the built-in exhalation ports in the TFM and the excessive air leaks around the mouth in the case of the FM. Excessive leakage can reduce the relative humidity of the inhaled air in NIV. Proper humidification could correct or prevent this problem. ${ }^{(30)}$

Two clinical studies of the TFM had been published. One evaluated a prototype of the TFM in 9 patients with chronic respiratory failure who presented intolerance to FMs or NMs. ${ }^{(13)}$ The authors found that the TFM prototype was associated with less discomfort and leakage. A more recent, retrospective, study evaluated the performance of a TFM identical to the one used in our study. ${ }^{(14)}$ The authors of that study evaluated the application of the TFM in patients with ARF who presented extensive leaks, poor mask tolerance or an inability to tolerate ventilation applied at the target levels, altered gas exchange and labored breathing when NMs or FMs were used. Use of the TFM stabilized gas exchange, diminished labored breathing, was well tolerated and averted endotracheal intubation in 8 of the 10 patients evaluated.

Claustrophobia has been more frequently reported for TFM use than for NM use. In the present study, the TFM also presented the highest scores for this side effect. This is the first report of its kind evaluating adverse effects related to TFM use. One possible explanation is that the TFM is much larger than are the other two masks. Our findings are discrepant from those of one group of authors who reported fewer incidents of claustrophobia for TFM use than for NM or FM use. ${ }^{(14)}$ Those authors stated that the TFM design maintains an unobstructed field of view and maintains the possibility of verbal communication, attenuating the claustrophobic sensation.

The partial pressure of exhaled $\mathrm{CO}_{2}$ entering the ventilator circuit remained at zero when the TFM was used. Two bench studies showed that the built-in exhalation ports of the TFM decrease the probability of rebreathing in comparison with other masks, especially if an EPAP of 4-6 $\mathrm{cmH}_{2} \mathrm{O}$ is applied. ${ }^{(21,23)}$ Our findings are consistent with the findings of those studies. Since we did not measure the exact amount of air leakage, we cannot exclude the possibility that leaks around the TFM also contributed to zeroing the exhaled $\mathrm{CO}_{2}$ entering the circuit. More leakage around the FM might also explain the lower partial pressure of exhaled $\mathrm{CO}_{2}$ entering the circuit when the FM was used than when the NM was used.

Our study had limitations. The use of a nonpatient sample makes it difficult to extrapolate our results to patients in ARF, and the use of volunteers has been associated with biases related to placebo and nocebo effects. The volunteers were clearly informed of the primary objective of the study, which was to compare the three types of masks, considering the lack of previous experimental or clinical data favoring one interface over another in terms of their propensity to provoke short-term adverse effects. This might have minimized these potential biases. ${ }^{(18)}$ Since there are no standardized, validated questionnaires designed to assess short-term adverse effects of NIV interfaces, it was necessary to devise one. The total time spent for each mask trial, including the periods of adaptation and the application of the two pressure settings, was 20-30 min. This period of time was sufficient for mask adjustments, as well as for the recognition and reporting of short-term adverse effects. Nevertheless, we cannot rule out the possibility that different types and intensities of adverse effects could occur if NIV were instituted for a longer period of time. Since we studied only one model of each type of mask, it is possible that different models, produced by the same or other manufacturers, would have yielded different results. ${ }^{(15,16)}$ 
The TFM is more expensive than is the NM or the FM. It also needs to be used with ventilators especially designed for NIV and capable of compensating for large air leaks. These aspects might constrain the utilization of this mask in institutions with limited access to financial or equipment resources.

In conclusion, the type and incidence of mask-related short-term adverse effects are related to mask type and NIV pressure levels. The clinical relevance of our findings can be summarized as follows: the TFM might be a reliable option for use in patients who adapt poorly to the NM or FM due to pain or skin damage on the bridge of the nose, as well as air leaks around the eyes or mouth; humidification should routinely accompany TFM use in order to prevent oronasal dryness; accumulation of exhaled $\mathrm{CO}_{2}$ in the circuit and consequent $\mathrm{CO}_{2}$ rebreathing do not constitute a problem when the TFM is used, although patients with claustrophobia might be less comfortable with the TFM than with the NM. The question of which short-term adverse effects or mask types are most associated with NIV failure or success in patients with ARF merits further investigation.

\section{References}

1. Keenan SP, Kernerman PD, Cook DJ, Martin CM, McCormack D, Sibbald WJ. Effect of noninvasive positive pressure ventilation on mortality in patients admitted with acute respiratory failure: a meta-analysis. Crit Care Med. 1997;25(10):1685-92.

2. Carlucci A, Richard JC, Wysocki M, Lepage E, Brochard L; SRLF Collaborative Group on Mechanical Ventilation. Noninvasive versus conventional mechanical ventilation. An epidemiologic survey. Am J Respir Crit Care Med. 2001;163(4):874-80.

3. Sociedade Brasileira de Pneumologia. 111 Consenso Brasileiro de Ventilação Mecânica. J Bras Pneumol. 2007;33(Supl 2):S51-S150

4. Meduri GU, Turner RE, Abou-Shala N, Wunderink R, Tolley E. Noninvasive positive pressure ventilation via face mask. First-line intervention in patients with acute hypercapnic and hypoxemic respiratory failure. Chest. 1996;109(1):179-93.

5. Pinheiro BV, Pinheiro AF, Henrique DMN, Oliveira JCA, Baldi J. Ventilação não-invasiva com pressão positiva em pacientes com insuficiência respiratória aguda. J Pneumol. 1998;24(1):23-29.

6. Holanda MA, Oliveira CH, Rocha EM, Bandeira RM, Aguiar IV, Leal W, et al. Ventilação não-invasiva com pressão positiva em pacientes com insuficiência respiratória aguda: fatores associados à falha ou ao sucesso. J Pneumol 2001;27(6):301-9.

7. Schettino G, Altobelli N, Kacmarek RM. Noninvasive positive-pressure ventilation in acute respiratory failure outside clinical trials: experience at the Massachusetts General Hospital. Crit Care Med. 2008;36(2):441-7.

8. Antonelli M, Conti G, Rocco M, Bufi M, De Blasi RA, Vivino G, et al. A comparison of noninvasive positivepressure ventilation and conventional mechanical ventilation in patients with acute respiratory failure. $\mathrm{N}$ Engl J Med. 1998;339(7):429-35.

9. Soo Hoo GW, Santiago S, Williams AJ. Nasal mechanical ventilation for hypercapnic respiratory failure in chronic obstructive pulmonary disease: determinants of success and failure. Crit Care Med. 1994;22(8):1253-61.

10. Mehta S, Hill NS. Noninvasive ventilation. Am J Respir Crit Care Med. 2001;163(2):540-77.

11. Hill NS. Complications of noninvasive positive pressure ventilation. Respir Care. 1997;42(4):432-42.

12. Ferguson GT, Gilmartin M. CO2 rebreathing during BiPAP ventilatory assistance. Am J Respir Crit Care Med. 1995;151(4):1126-35.

13. Criner GJ, Travaline JM, Brennan KJ, Kreimer DT. Efficacy of a new full face mask for noninvasive positive pressure ventilation. Chest. 1994;106(4):1109-15.

14. Roy B, Cordova FC, Travaline JM, D’Alonzo GE Jr, Criner GJ. Full face mask for noninvasive positive-pressure ventilation in patients with acute respiratory failure. $\mathrm{J}$ Am Osteopath Assoc. 2007;107(4):148-56.

15. Gregoretti C, Confalonieri M, Navalesi P, Squadrone V, Frigerio P, Beltrame F, et al. Evaluation of patient skin breakdown and comfort with a new face mask for non-invasive ventilation: a multi-center study. Intensive Care Med. 2002;28(3):278-84.

16. Mediano 0, García-Río F, Villasante C. Comparison of carbon dioxide rebreathing during application of continuous positive airway pressure with 3 types of nasal mask [Article in Spanish]. Arch Bronconeumol. 2006;42(4):189-93.

17. Hill NS. Saving face: better interfaces for noninvasive ventilation. Intensive Care Med. 2002;28(3):227-9.

18. Russell WC, Greer JR. The comfort of breathing: a study with volunteers assessing the influence of various modes of assisted ventilation. Crit Care Med. 2000;28(11):3645-8.

19. Massie CA, Hart RW. Clinical outcomes related to interface type in patients with obstructive sleep apnea/ hypopnea syndrome who are using continuous positive airway pressure. Chest. 2003;123(4):1112-8.

20. Lofaso F, Brochard L, Touchard D, Hang T, Harf A, lsabey D. Evaluation of carbon dioxide rebreathing during pressure support ventilation with airway management system (BiPAP) devices. Chest. 1995;108(3):772-8.

21. Schettino GP, Chatmongkolchart S, Hess DR, Kacmarek RM. Position of exhalation port and mask design affect CO2 rebreathing during noninvasive positive pressure ventilation. Crit Care Med. 2003;31(8):2178-82.

22. Schettino GP, Tucci MR, Sousa R, Valente Barbas CS, Passos Amato MB, Carvalho CR. Mask mechanics and leak dynamics during noninvasive pressure support ventilation: a bench study. Intensive Care Med. 2001;27(12):1887-91.

23. Saatci E, Miller DM, Stell IM, Lee KC, Moxham J. Dynamic dead space in face masks used with noninvasive ventilators: a lung model study. Eur Respir J. 2004;23(1):129-35.

24. Cavaliere F, Masieri S, Conti G, Antonelli M, Pennisi MA, Filipo R, et al. Effects of non-invasive ventilation on 
middle ear function in healthy volunteers. Intensive Care Med. 2003;29(4):611-4.

25. Pépin JL, Leger P, Veale D, Langevin B, Robert D, Lévy P. Side effects of nasal continuous positive airway pressure in sleep apnea syndrome. Study of 193 patients in two French sleep centers. Chest. 1995;107(2):375-81.

26. Kalan A, Kenyon GS, Seemungal TA, Wedzicha JA. Adverse effects of nasal continuous positive airway pressure therapy in sleep apnoea syndrome. J Laryngol Otol. 1999;113(10):888-92.

27. Navalesi P, Fanfulla F, Frigerio P, Gregoretti C, Nava S. Physiologic evaluation of noninvasive mechanical ventilation delivered with three types of masks in patients with chronic hypercapnic respiratory failure. Crit Care Med. 2000;28(6):1785-90.
28. Kwok H, McCormack J, Cece R, Houtchens J, Hill NS. Controlled trial of oronasal versus nasal mask ventilation in the treatment of acute respiratory failure. Crit Care Med. 2003;31(2):468-73.

29. Antón A, Tárrega J, Giner J, Güell R, Sanchis J. Acute physiologic effects of nasal and full-face masks during noninvasive positive-pressure ventilation in patients with acute exacerbations of chronic obstructive pulmonary disease. Respir Care. 2003;48(10):922-5.

30. Martins De Araújo MT, Vieira SB, Vasquez EC, Fleury B. Heated humidification or face mask to prevent upper airway dryness during continuous positive airway pressure therapy. Chest. 2000;117(1):142-7.

\section{About the authors}

\section{Marcelo Alcantara Holanda}

Adjunct Professor in the Department of Clinical Medicine. Federal University of Ceará School of Medicine, Fortaleza, Brazil.

\section{Ricardo Coelho Reis}

Pulmonologist. Federal University of Ceará Walter Cantídio University Hospital, Fortaleza, Brazil.

\section{Georgia Freire Paiva Winkeler}

Pulmonologist. Federal University of Ceará Walter Cantídio University Hospital, Fortaleza, Brazil.

\section{Simone Castelo Branco Fortaleza}

Pulmonologist. Federal University of Ceará Walter Cantídio University Hospital, Fortaleza, Brazil.

\section{José Wellington de Oliveira Lima}

Biostatistics Consultant. Federal University of Ceará Walter Cantídio University Hospital, Fortaleza, Brazil.

\section{Eanes Delgado Barros Pereira}

Adjunct Professor in the Department of Clinical Medicine. Federal University of Ceará School of Medicine, Fortaleza, Brazil. 
Appendix 1 - Questionnaire regarding the type and intensity of short-term adverse effects of NIV masks.

Below is a list of problems people might experience when receiving noninvasive ventilation delivered via a mask. Please indicate how much of a problem each of the items listed below presented during the period of mask use. If you experienced a problem not included on this list, please explain at the bottom of this page. The choices are as follows: (0) not a problem, (1) a slight problem, (2) a moderate problem, and (3) a major problem.

Problems / Intensity 0123

Pain

1. Pain on the forehead

2. Pain at the bridge of the nose

3. Pain on the cheeks

4. Pain on the chin (not applicable to the nasal mask)

Unpleasant air leaks from the mask

5. Air leaks around the eyes

6. Air leaks around the mouth

Oronasal dryness

7. Dry mouth or throat

8. Dry or congested nose

Other

9. Pressure from the mask

10. Skin irritation*

11. Claustrophobia from the mask

*itching or burning sensation on the skin

Problems not included in the list above: 